\title{
Modeling Road Network Vulnerability for Evacuees and First Responders in No-Notice Evacuation
}

\author{
Xiang Chen ${ }^{1,2}$ and Qiang $\mathrm{Li}^{1}$ \\ ${ }^{1}$ School of Natural Resources, Faculty of Geographical Science, Beijing Normal University, Beijing 100875, China \\ ${ }^{2}$ Department of Emergency Management, Arkansas Tech University, Russellville, AR 72801, USA \\ Correspondence should be addressed to Xiang Chen; chenxiangpeter@gmail.com
}

Received 15 February 2017; Accepted 10 April 2017; Published 14 May 2017

Academic Editor: Dongjoo Park

Copyright (c) 2017 Xiang Chen and Qiang Li. This is an open access article distributed under the Creative Commons Attribution License, which permits unrestricted use, distribution, and reproduction in any medium, provided the original work is properly cited.

\begin{abstract}
The concept of vulnerability has been employed to develop transport systems that sustain devastating disasters and ensure the efficient evacuation of neighborhoods. Existing studies of road network vulnerability overlook two important aspects of analysis: the no-notice evacuation and the different objectives of evacuees and first responders. First, a no-notice evacuation leaves limited time for proactive emergency planning; therefore, rescue strategies in this scenario rely heavily on real-time traffic information. Second, the goal of first responders in an evacuation is to move into an affected area immediately after a hazardous event unfolds, and the risk they face differs from that of evacuees. To this end, this paper develops a network-based model to evaluate vulnerability during a no-notice evacuation and applies it to a case study in Dublin, OH, USA. The model is suited to assessing network vulnerability in response to events with uncertainty and coordinating traffic control strategies in a no-notice evacuation. This study can become a valuable complement to the methodological conceptualization of vulnerability and can provide insights into developing comprehensive emergency management plans.
\end{abstract}

\section{Introduction}

Vulnerability manifests itself in hazardous situations [1]. It is defined as the degree to which a system is exposed to potential hazards and attacks $[2,3]$. The vulnerability of critical infrastructure during mass evacuations, in such areas as transport corridors and transit terminals, could have a significant impact on evacuation efficiency and the severity of damage incurred. Identifying the vulnerability of critical infrastructure is key to predicting the likelihood of neighborhoods experiencing devastating events, such as terrorist attacks and chemical spills. In order to alleviate the consequence of such incidents, one component of effective evacuation planning is to assess the level of vulnerability as a way to increase preparedness and reduce the loss of life and property arising from the incidents.

Vulnerability analysis relies on mathematical modeling of road networks, in which transport systems are abstracted into networks or graphs, with lines representing road segments and nodes as intersections and critical facilities [4]. Analyzing the spatial attributes and topological configuration of networks is essential for gaining an improved understanding of how transport systems are structured to maintain usage levels during a period of system failure [5]. Network analysis has become a topical field in emergency management, as it overcomes the arbitrariness of multicriteria evaluation employed in area-based analysis [6-8].

Two important facets have been overlooked in the assessment of road network vulnerability. The first pertains to the type of evacuation, which could result in very different threat levels [9]. Hazards can be broadly categorized as short-notice and no-notice depending on the period of time allowed for evacuation preparation. Short-notice hazards, such as earthquakes and tornadoes, are usually broadcast 24-72 hours ahead of the events [10]. Adopting proactive response strategies, such as contraflow traffic control, optimal 
routing to shelters, and preparedness of emergency supplies, could help reduce the destruction and loss of life to a great extent [10]. No-notice hazards, such as terrorist attacks and chemical spills, take place without a priori expectation [1113]. In response to no-notice hazards, it is nearly impossible to estimate the development of the scenario, including the magnitude, duration, and severity of the incidents. When disaster strikes without warning, effective communication of real-time traffic information is essential [11]. Studies of no-notice evacuations are limited in scope as modeling the uncertainty of built environment poses a considerable challenge $[12,13]$.

The second overlooked facet pertains to the fact that the two groups of people involved in an evacuation, evacuees and first responders, face very different types of threats [14]. While evacuees are subject to imminent danger, their intuitive response to a life-threatening situation is to move away from at-risk areas [15]. However, it is the mission of first responders to support and implement rescue orders by denying their instincts and moving into the affected areas. The risk to which they are exposed may be even greater in a no-notice scenario due to scarce resources and limited information in the response phase [16]. Differentiating the vulnerabilities faced by evacuees and first responders is of crucial importance for customizing response strategies that ensure the safety of both groups.

These two critical issues demand a rethinking of the notion of vulnerability. In other words, we must measure vulnerability not only by maintaining accurate geographic dimensions but also by including empirical observations of no-notice hazards and an understanding of the different motivations and needs between evacuees and first responders. To achieve this goal, the paper develops a network-based vulnerability assessment model by identifying road structure prone to evacuation difficulty in the event of no-notice evacuations. This paper not only includes the methodological formulation of the problem but also estimates traffic patterns as well as the different needs and response objectives of the evacuees and first responders. By identifying neighborhoods that are more likely to suffer evacuation difficulty, emergency planners can gain an overarching understanding of the areas in the greatest need of coordination. This knowledge can facilitate many immediate actions, such as efficient allocation of relief resources to neighborhoods when incidents occur without expectation.

The paper is structured as follows. Section 2 is a review of methods for evaluating vulnerability via network analysis. Section 3 proposes the model that identifies the evacuation risk moving into and out of a network-based region. The specific details of the travel environment, such as road capacity, direction of travel, and speed limits are also incorporated into the model. Section 4 presents a case study that implements the model in a suburban community of Columbus, $\mathrm{OH}$, USA. The results derived from the Geographic Information Systems (GIS) show two different levels of vulnerabilities on the road level for evacuees and first responders in a no-notice situation. This finding is supplemented by sensitivity analysis of the model by examining the model parameters in Section 4 , followed by the conclusions in Section 5 .

\section{Analysis of Road Network Vulnerability}

To date, there is no consensus on the definition of vulnerability, as it incorporates a variety of foci (e.g., physical, political, and social), a range of paradigms (e.g., hard, soft, and critical), and different modes of impact measurement [17]. Traditional analysis of vulnerability is a decision-making process dependent on the built environment as well as judgments of participants. Multicriteria evaluations, such as the Analytic Hierarchy Process (AHP) that integrates potential socioeconomic loss by geographic unit (e.g., census tract and state), are adopted. In this process, losses from a disaster scenario are predicted by analyzing a series of predetermined physical, environmental, and socioeconomic factors (e.g., distance to earthquake faults, housing quality, and potentially affected population) under a given ranking criterion $[6-8,18$, 19]. Although the AHP is relatively practical in arriving at a collective decision due to its simplicity of implementation, it has been criticized for the arbitrariness in weighting the determinants and the change of ranks when new alternatives are introduced [20]. More importantly, AHP is highly susceptible to the modifiable areal unit problem (MAUP), referring to the fact that spatial patterns are affected by the delineation of geographic units [21]. In reality, emergency systems are made up of interconnected parts where a hazardous event could trigger cascading effects in adjacent units. For example, a power outage in a target area will impact neighboring areas [22]. As the AHP overlooks the inherent connectivity between critical facilities, its application to vulnerability analysis is questioned.

To overcome these setbacks, recent emergency management studies have begun to create network models with an emphasis on critical infrastructure. These efforts highlight network topological characteristics (e.g., accessibility, connectivity, and captivity) and are able to overcome the lack of connectivity in area-based studies. The goal of network vulnerability analysis is to identify the worst scenario in which disabled network elements could disrupt the entire system [17]. This worst-case analysis relies on normative models under the constraints of travel environment (e.g., road capacity, travel demand). For example, the integral accessibility measurement can be employed to estimate the worst-case scenario of how link failures could impact other parts of the road network [23, 24]; critical infrastructure, in terms of vital transport nodes/links, can be identified by modeling the highest potential loss of efficiency in highway networks $[25,26]$; vulnerable roads can be identified by heuristic models that demarcate at-risk neighborhoods [2730]. A subsequent mapping of the vulnerability in the context of GIS can further help identify the deficiencies in road networks that may hinder efficient evacuations [27]. These high-risk neighborhoods can then be enhanced by sufficient rescue resources and improved connectivity systems in the phase of preparedness.

Analysis of road networks has demonstrated that the vulnerability of a region is not only arbitrarily dictated by existing socioeconomic factors per se but also limited by the spatial organization of the transport system. This type of analysis has strengthened the perception that vulnerability 
is beyond the likelihood of loss; it also manifests in the geographic dimension that plays an integral role in connecting places [31]. Viewing the vulnerability of a region as the clearance time of evacuation is essentially important for a short-notice evacuation where the location or trajectory of a hazard is predictable and a degree of readiness is available [32]. For example, contraflow traffic control has significantly improved the efficiency of movement in shortnotice evacuations. However, such operations are heavily dependent on a priori knowledge of hazards and often require three to five hours to establish [33,34]. In the case of a no-notice evacuation, both the time and resources allowed for preparation are limited. Thus, the planning process must emphasize flexibility in operations and may not conform to well-structured strategies $[13,35]$. For example, if a nonotice hazard occurs during rush hours, there may not be sufficient time to reverse the lanes and regulate the traffic [13]. Under such abrupt circumstances, travel between two locations is still rigorously regulated by the traffic code, such as speed limits and direction of travel. Thus, modeling road network vulnerability for a no-notice evacuation should incorporate the regulatory code that exists in the normal travel environment.

A less elucidated area in no-notice evacuations is the added risk level for first responders. Unlike evacuees whose course of action is oriented towards fleeing the danger zone, the movements of first responders are more complex. Their actions include improving the situational awareness of evacuees, providing relief resources, and assisting with vehicle routing as events unfold [16]. These actions invariably lead to movement into the danger zone and would expose the first responders to a higher likelihood of injuries and fatalities [36]. The situation is exacerbated in a nonotice evacuation, as traffic management tactics cannot be immediately employed at the initial phase of deployment and thus the commuting traffic may hinder effective rescue $[13,14]$. The nature and scope of the evacuation risk that first responders cope with must be well understood and scientifically estimated in order to alleviate the risks arising from compromised evacuation plans. To date, such critical factors have not been well investigated in existing research on road network vulnerability.

\section{Modeling Outbound and Inbound Vulnerabilities}

3.1. Illustration of the Problem. This section proposes the Evacuation Vulnerability Model (EVM) to illustrate and evaluate the road network vulnerability faced by evacuees and first responders in no-notice evacuations. The model is extended from the Critical Cluster Model (CCM) that estimates evacuation vulnerability at the neighborhood scale [27-30]. In the model, the difficulty of movement in an evacuation is considered to be access to and from nodes in a network-based travel environment. This difficulty of access is interpreted by the vulnerability ratio depicted in

$$
\text { Vulnerability Ratio }=\frac{T}{C} \text {. }
$$

In this equation, the vulnerability ratio represents the difficulty of travel and the potential for traffic congestion for the node of interest (referred to as the anchor node), where $T$ is the total volume of traffic flow and $C$ is the capacity of roads (e.g., number of lanes). When this ratio reaches its maximum, it creates the most difficult scenario for vehicles at the anchor node to relocate and can be used to measure the evacuation vulnerability at this node.

As discussed in the last section, the evacuation risks faced by evacuees and first responders need to be carefully differentiated. When hazards strike without notice, evacuees tend to intuitively move away from the affected area while first responders are moving into the area to implement rescue orders. Monitoring these two types of travel can be accomplished by measuring the evacuation vulnerability as the outbound risk (for evacuees) and the inbound risk (for first responders). These two types of vulnerabilities are discussed in detail below.

Outbound Evacuation Vulnerability. Outbound evacuation vulnerability (OEV) characterizes the difficulty for evacuees to travel away from a node. This measurement identifies the most difficult situation when moving away from the anchor node. It is measured by maximizing the vulnerability ratio of all outbound traffic (departure traffic originating from the region, $\left.T_{\text {out }}\right)$ to the total exits of the region $\left(C_{\text {out }}\right)$, as depicted in

$$
\mathrm{OEV}=\max \left(\frac{T_{\text {out }}}{C_{\text {out }}}\right) .
$$

An additional constraint on the problem is the direction of travel. In a no-notice evacuation, driving directions are rigorously restricted; and, in this case, eligible exits are defined as the road segments that permit only outbound travel. This restriction can also be found in variations of the CCM $[29,30]$. Figure 1 illustrates an example of this outbound evacuation vulnerability for node $\mathrm{A}$, the anchor node in the sample network. If each node has one unit of outbound traffic and each arrow represents a single lane, Figure 1(a) shows the vulnerability ratio of $T_{\text {out }}$ to $C_{\text {out }}$ for node $\mathrm{A}$ as one (i.e., one unit of outbound traffic through exit $A B$ ). Then, the search region (which must include the anchor node A) keeps expanding until reaching a given limit. For example, Figure 2(b) shows that this ratio increases to two when the search region includes both nodes $\mathrm{A}$ and $\mathrm{B}$ (i.e., two units of outbound traffic through exit $\mathrm{BC}$ ). When the region includes four nodes: A, B, C, and D, the ratio reaches its maximum of four (i.e., four units of outbound traffic through exit DE). This maximum value represents the OEV of the anchor node A, a situation where evacuees from node A may encounter the highest level of movement difficulty when leaving the area. Figure 1(d) shows that node A's outbound vulnerability ratio varies by the size of the search region and reaches the maximum at four nodes. After node A's OEV is identified, the method can be subsequently applied to other nodes of the network and thus derives their levels of vulnerability.

Inbound Evacuation Vulnerability. Similarly, inbound evacuation vulnerability (IEV) represents the most difficult scenario 


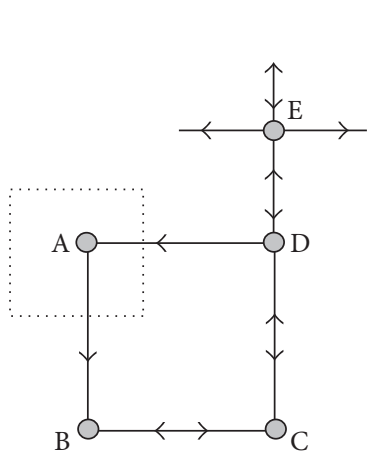

(a)

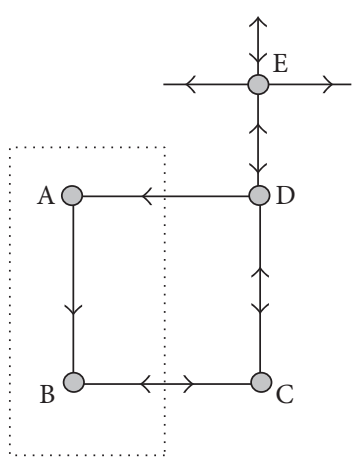

(b)

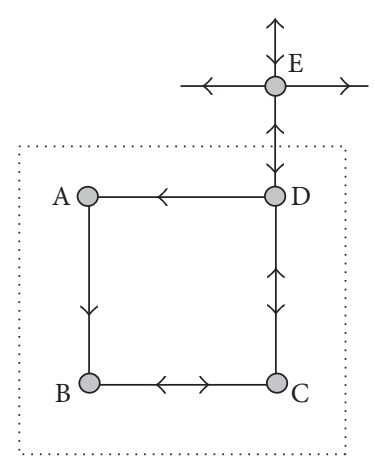

(c)

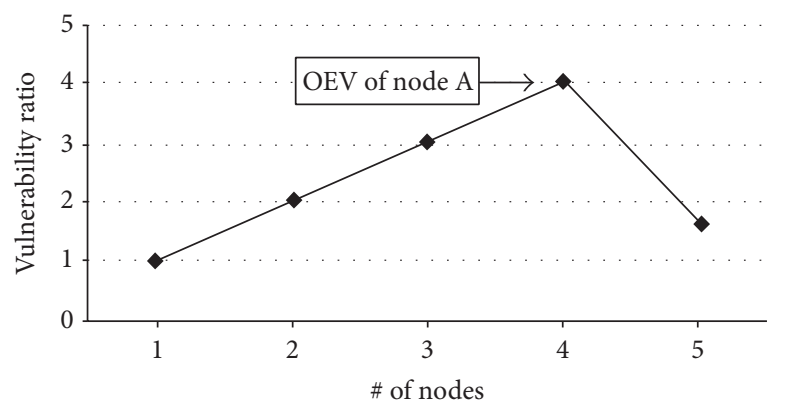

(d)

FIGURE 1: The procedure of searching for the OEV of anchor node A: (a) the search region includes only node A; (b) the search region includes nodes A and B; (c) the search region includes four nodes, where the ratio reaches its maximum and node A's OEV is derived; (d) the relationship between node A's outbound vulnerability ratio and the number of nodes in the search region.

for the first responders who must travel into the site. It is measured by maximizing the vulnerability ratio of all inbound traffic (arrival traffic destined for the region, $T_{\text {in }}$ ) to the total entrances of the region $\left(C_{\text {in }}\right)$, as depicted in

$$
\mathrm{IEV}=\max \left(\frac{T_{\text {in }}}{C_{\text {in }}}\right)
$$

Measuring IEV is similar to the procedure of OEV. The search region expands from including only the anchor node per se to a predefined search boundary in order to derive the maximum vulnerability ratio. The only difference is that instead of accounting for exits, the method now considers entrances, referring to the lanes leading into the region. For the sake of simplicity, the search for the IEV is not illustrated in a step-by-step process. Figure 2(a) shows the scenario where traffic headed towards node A may encounter the highest level of movement difficulty. This is the search region within which anchor node A's IEV is derived. Figure 2(b) shows that A's inbound vulnerability ratio varies by the size of the search region and reaches the maximum at five nodes.

3.2. Formulation. It can be seen from the illustration that the model enumerates all combinations of nodes in a search for the ratio that represents the bottleneck travel scenario. The model is also subject to three graph constraints that (1) the search region contains the anchor node, (2) the search region has an upper boundary, and (3) the network is continuous [27].

One remaining issue is the representation of road capacity. This factor can be estimated by consolidating the number of lanes and road speed limits, because a higher speed limit allows for faster movement. Based on this premise, two evacuation vulnerability indices are derived by defining road capacity as the number of lanes weighted by the speed limits $\left(V_{\text {out }}\right.$ and $V_{\text {in }}$ ), as illustrated by (4). Although these two equations may not fully explain the intrinsic nature of evacuation efficiency, they do imply that these two components are essential mediators of road capacity.

$$
\begin{gathered}
\mathrm{OEV}=\max \left(\frac{T_{\text {out }}}{V_{\text {out }} C_{\text {out }}}\right) \\
\mathrm{IEV}=\max \left(\frac{T_{\text {in }}}{V_{\text {in }} C_{\text {in }}}\right) .
\end{gathered}
$$

It is necessary to clearly state this problem in a mathematical form to better understand the nuances. Equations (5) through (13) have been developed to formulate the respective measures of OEV and IEV based on the original CCM [27, 28].

Given a continuous graph $V$, the objective is to find a section $V_{r}$ of $V$ that includes node $r$ and is limited in size (with a maximum of $s$ nodes). This section $V_{r}$ maximizes the vulnerability ratio defined by the objective function (5). Node 


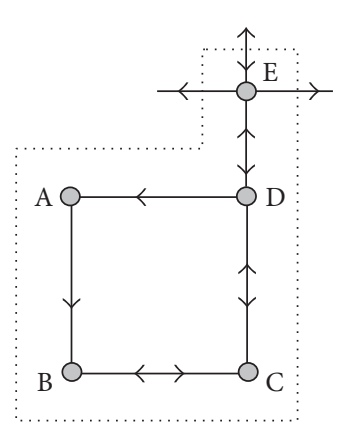

(a)

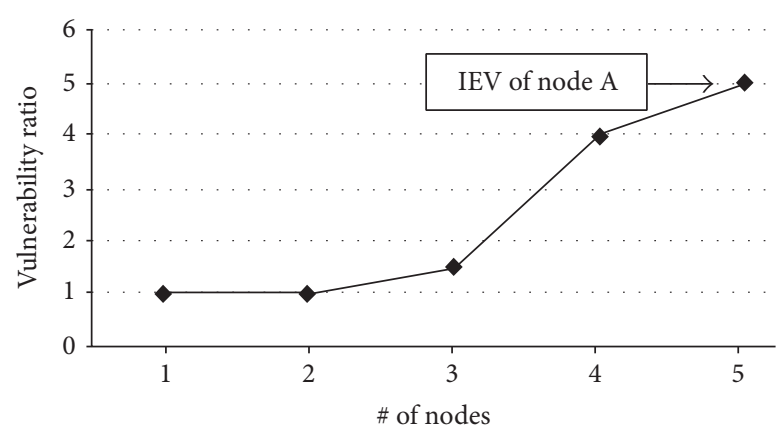

(b)

FIgURE 2: The procedure of searching for the IEV of anchor node A: (a) when the region includes five nodes, the ratio reaches its maximum and node A's IEV is derived; (b) the relationship between node A's inbound vulnerability ratio and the number of nodes in the search region.

$r$ 's outbound evacuation vulnerability $\left(\mathrm{OEV}_{r}\right)$ is defined as follows:

Objective is

$$
\mathrm{OEV}_{r}=\max \frac{\sum_{i} a_{i} x_{i}}{\sum_{i} \sum_{j} C_{i j} y_{i j} V_{i j} z_{i j}}
$$

subject to

$$
\begin{aligned}
\left\|x_{i}-x_{j}\right\| & \leq y_{i j} \\
\sum_{i} x_{i} & \leq s \\
x_{i}, y_{i j}, z_{i j} & \in\{0,1\} \quad \forall i, j \in V,
\end{aligned}
$$

where

$$
\begin{aligned}
& x_{i}= \begin{cases}1 & \text { if node } i \text { is in } V_{r} \\
0 & \text { otherwise }\end{cases} \\
& y_{i j} \\
&= \begin{cases}1 & \text { if node } i \text { is in } V_{r} \text { and node } j \text { is not in } V_{r} \\
0 & \text { otherwise }\end{cases} \\
& z_{i j}= \begin{cases}1 & \text { if travel from node } i \text { to } j \text { is permitted } \\
0 & \text { otherwise, }\end{cases} \\
& a_{i}: \text { outbound traffic originated at node } i, \\
& C_{i j}: \text { number of lanes of road } i j \text { in one direction, } \\
& s: \text { maximum nodes in the search region, } \\
& r \text { index of the anchor node, } \\
& V_{i j}: \text { speed limit of road } i j .
\end{aligned}
$$

Equation (5) is the objective function maximizing the ratio of outbound traffic to the exits of a region. This maximum ratio is the OEV of the anchor node $r$. The numerator of (5) includes a binary variable $x_{i}$ to consolidate all outbound traffic in a search region, as defined by (9). The denominator of (5) specifies that an eligible exit of the search region is subject to two binary variables $y_{i j}$ and $z_{i j}: y_{i j}$ controls if road $i j$ traverses the boundary of the $V_{r}$ section, as defined by (10) and $z_{i j}$ controls the travel direction of road $i j$, as defined by (11). If the two end-nodes of road $i j$ are positioned on either side of the boundary of the search region, and the road is headed outward, $y_{i j}$ and $z_{i j}$ will both be one, road $i j$ will then be considered an eligible exit, and the number of lanes $c_{i j}$ and speed limit $v_{i j}$ will be included in the total exit capacity. Equation (6) states that if two end-nodes are in two subsets, $y_{i j}$ has to be one. Equation (7) ensures that the size of the search region cannot exceed a maximum of $s$ nodes. Equation (8) specifies that $x_{i}, y_{i j}$, and $z_{i j}$ are binary variables.

Similarly, the inbound evacuation vulnerability $\left(\operatorname{IEV}_{r}\right)$ for node $r$ can be formulated with minor revisions from the previous formulation, as shown in (12) and (13).

Objective is

$$
\mathrm{IEV}_{r}=\max \frac{\sum_{i} b_{i} x_{i}}{\sum_{i} \sum_{j} C_{i j} y_{i j} V_{i j} z_{i j}}
$$

subject to (6) (7) (8),

where notations follow the former formulation, except

$$
z_{i j}= \begin{cases}1 & \text { if travel from node } j \text { to } i \text { is permitted } \\ 0 & \text { otherwise }\end{cases}
$$

$$
b_{i} \text { : inbound traffic headed towards node } i \text {. }
$$

The changes made to the equation above are reflected in the objective function (12) and the definition of an eligible entrance, whose direction is constrained by the binary variable $z_{i j}$ in (13). Equation (12) specifies that the IEV of the anchor node is derived from a region where the ratio of inbound traffic (i.e., the numerator) to the weighted road capacity of all entrances (i.e., the denominator) is maximized.

These two effects of vulnerability are derived at nodes. The risk pattern can be better understood through visualization on road segments. Although there are many ways to generate 


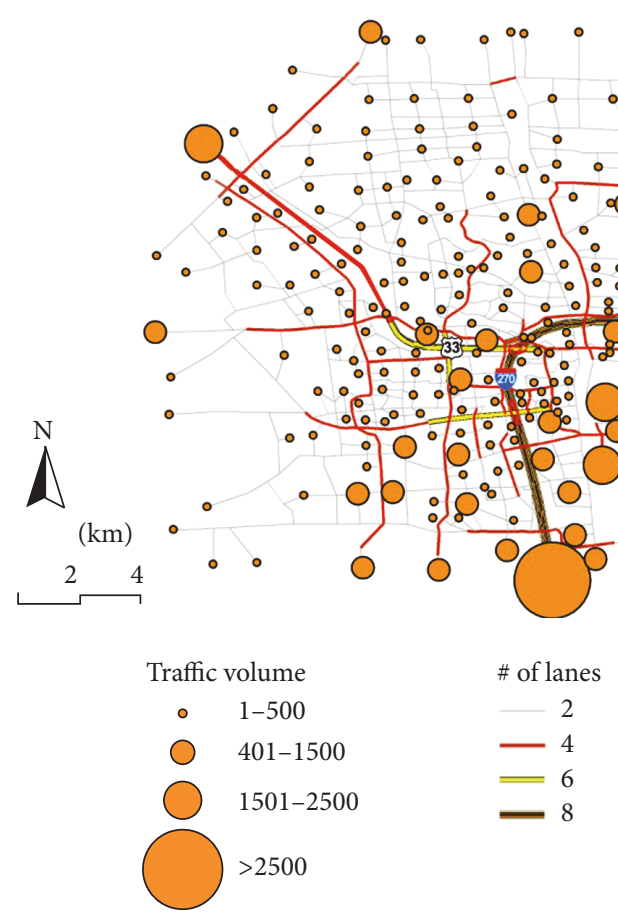

(a) Outbound traffic
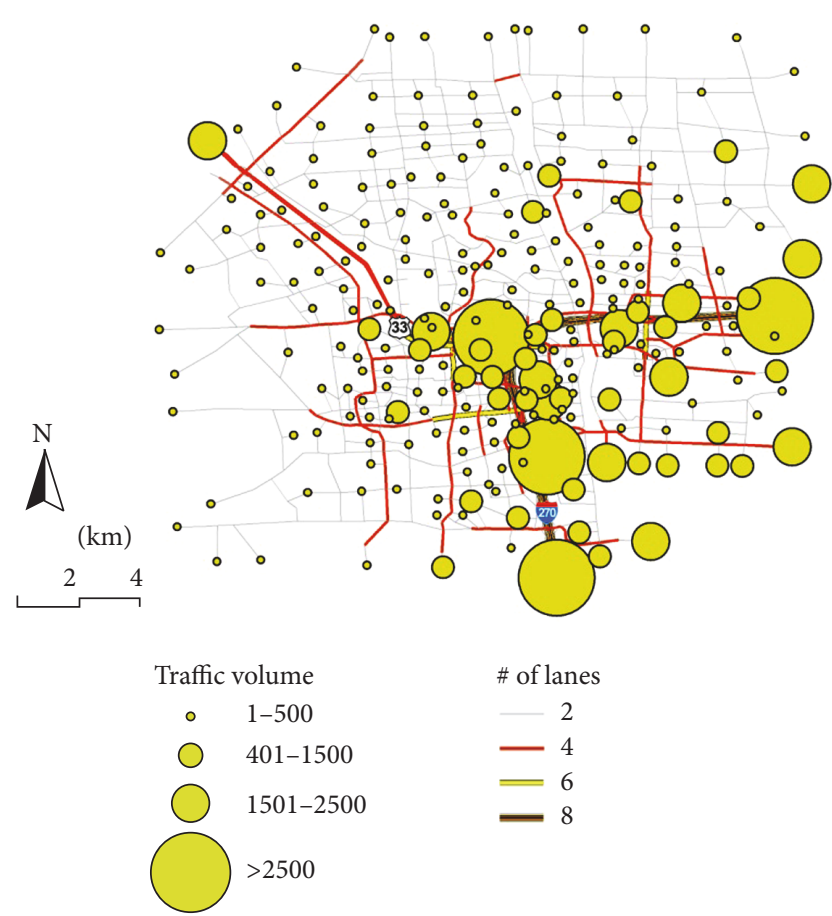

(b) Inbound traffic

FIGURE 3: The layout of the transport network in Dublin with (a) the cumulative outbound traffic volume and (b) the cumulative inbound traffic volume.

the segment value by referring to the attributes of its two endnodes (e.g., min, max, and mean), in this study, the average of the two end-nodes is adopted to represent the vulnerability of a road segment. Classifying vulnerability in a GIS will help to identify neighborhoods that are likely to suffer from traffic congestion for two differentiated groups: evacuees and first responders. In the next section, the method is applied to a real-world travel scenario, where further discussion of this model is provided.

\section{Case Study: Road Network Vulnerability in Suburban Columbus, $\mathrm{OH}$}

4.1. Background. Dublin is a suburban community located in Northwest Columbus, OH, USA. According to the 2015 census, the community covers an area of $64.2 \mathrm{~km}^{2}$ and has a residential population of 45,098 . There are two major highways, I-270 and US-33, in the region. The data includes all transport characteristics of the road network and morning peak hour Origin-Destination (OD) flow patterns [37]. By consolidating OD flow at the nodal location, the cumulative outbound and inbound traffic from and to each node can be derived. These two nodal indices were used to approximate the real-time traffic demand in an evacuation. Because Dublin is an open system with traffic flowing in and out to other areas, nodes on the fringe of the area can be regarded as gateways through which external traffic passes. In the model, the external traffic is treated as local traffic departing from and arriving at the gateway nodes. A bird's eye view of the region with two different traffic patterns is shown in Figure 3, which represents the traffic that evacuees and first responders may possibly encounter in a no-notice evacuation. It must be noted that because the datasets were collected from an earlier network study, they no longer reflect current traffic status.

4.2. Results. The EVM model was implemented on the platform of ESRI ArcGIS Desktop 10.3. Although ArcGIS is a powerful tool for manipulating spatial databases and visualizing geographic features, it falls short in its capability to develop a generic algorithm for optimization purposes. For this reason, all the datasets were initially geocoded in ArcGIS and exported to a text file for external processing. Microsoft Visual C++ was adopted as the external platform for customizing the optimization algorithm. OEV and IEV for both nodes and road segments in the network were derived using $\mathrm{C}++$ and were imported back to ArcGIS for visualization.

Figure 4 shows the evacuation vulnerability with a maximum search region of 20 nodes. Both the OEV (Figure 4(a)) and IEV levels (Figure 4(b)) are reflected in the road segments of the network. The two graphics illustrate the ratios under the same classification scheme with five categories ranging from low-risk (dark blue) to high-risk (red). Road network vulnerability between evacuees and first responders can be identified by comparing the results. First, the results with regard to the vulnerability levels of the two populations are very similar, indicating that evacuees and first responders face a similar level of evacuation risk regardless of their purposes of movement. This result can be explained by analyzing the original traffic data, which shows similar outbound and 


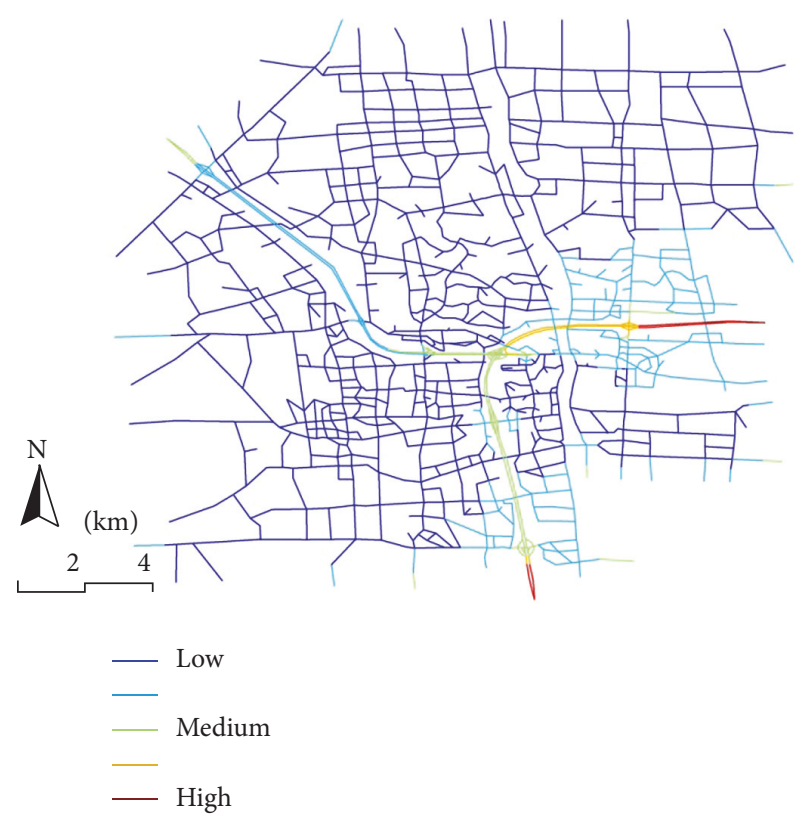

(a) OEV

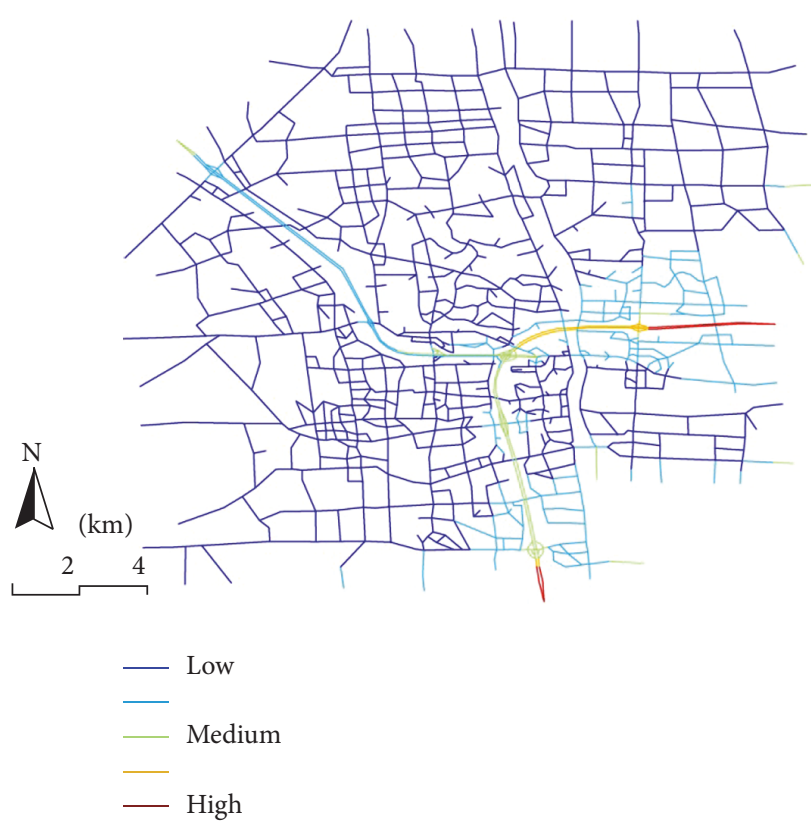

(b) IEV

FIGURE 4: The evacuation vulnerability in the study area for (a) evacuees and (b) first responders (search boundary $=20$ nodes).

inbound traffic patterns. Secondly, both figures depict high levels of evacuation difficulty on two highways, I-270 and US33 , which surprisingly echoes the normal traffic pattern in this region. Although highways have larger road capacities due to an increased number of lanes and higher speed limits than local streets, they are more vulnerable in no-notice evacuations because of fewer outlets for dispersing traffic [38]. This observation further verifies that the road topology plays an integral role in dictating evacuation vulnerability. Third, the vulnerability at the two ends of I-270 appears to be overstated. This can be attributed to the added traffic from external regions. Future studies should focus on better incorporating this external traffic to improve the rigor of the assessment.

4.3. Discussion. Although this study has revealed some interesting findings of the evacuation difficulty faced by both evacuees and first responders, questions arise about the validity of the model. Validating a vulnerability model is always challenging because the course of evacuation cannot be replicated in reality and the actual travel patterns vary by time of day. However, a similar goal can be achieved by analyzing the sensitivity of the model. It would be of significance to explore how the results could be affected by different model variables and how the model validity can be ensured by adding variations to the scenario. The section further elaborates the vulnerability levels faced by evacuees and first responders in two different cases.

Sensitivity Analysis of Search Boundary. The search boundary is the size of the search region, beyond which the search for the evacuation vulnerability is terminated. As a limitation of the CCM, the search boundary is a variable yet to be explored [27]. Because the search boundary of the case is originally given as 20 nodes, it would be interesting to test if the OEV and IEV patterns are sensitive to the variable change so as to establish a robust criterion for future applications.

The model was run with the search boundaries of 10 , 15,20 , and 25 nodes, respectively. The result for the OEV is shown in Figure 5 and Table 1. The result for IEV is shown in Table 2. As the search boundary expands, the mean OEV and IEV significantly increase while the increase of the standard deviation (SD) is minor (Figure 5(d)). The same pattern is observed on both nodes and lines (Tables 1 and 2). This result is informative as the maximum search boundary characterizes the impact of the no-notice event in areas that need to be immediately evacuated. The result indicates that the overall vulnerability of evacuees and responders in facing such a no-notice event will escalate as the magnitude of the hazard increases. However, by comparing Figures 5(a)-5(c), it becomes apparent that the overall spatial patterns are very similar, indicating that the increase in hazard impact will not alter the risk distribution. The observation suggests that a careful examination of the model variable is crucial because a small value may restrict the impact of the hazard and a large value may overstate the effect. Therefore, a precise definition of the variable is needed prior to the model implementation and is dependent on the nature and impact of the no-notice event, such as the release level of a chemical spill [39].

Scenario-Based Assessment. As no-notice evacuations are unpredictable, scenario-based assessment has been readily used to answer "what if" questions regarding changes made to the initial scenario and test the validity of the models [13, 26, 40, 41]. 
TABLE 1: Statistics of OEV in relation to the maximum search boundary in the study area.

\begin{tabular}{|c|c|c|c|c|c|}
\hline \multicolumn{6}{|c|}{$\mathrm{OEV}^{\dagger}$} \\
\hline Maxim & $y$ (nodes) & 10 & 15 & 20 & 25 \\
\hline \multirow{4}{*}{ Node } & Min & 0.0 & 1663.6 & 2800.0 & 3268.2 \\
\hline & Max & 1502930.0 & 1502930.0 & 1502930.0 & 1502930.0 \\
\hline & Mean & 29235.5 & 39597.0 & 50956.7 & 59378.0 \\
\hline & $\mathrm{SD}$ & 116835.3 & 121772.0 & 124148.9 & 124776.2 \\
\hline \multirow{4}{*}{ Line } & Min & 673.9 & 1690.5 & 2905.4 & 3477.5 \\
\hline & Max & 1502930.0 & 1502930.0 & 1502930.0 & 1502930.0 \\
\hline & Mean & 25919.6 & 35813.9 & 46683.0 & 54829.2 \\
\hline & SD & 102158.6 & 107035.4 & 110020.1 & 111084.1 \\
\hline
\end{tabular}

${ }^{\dagger}$ Measurement unit is vehicles/(lanes * MPH).

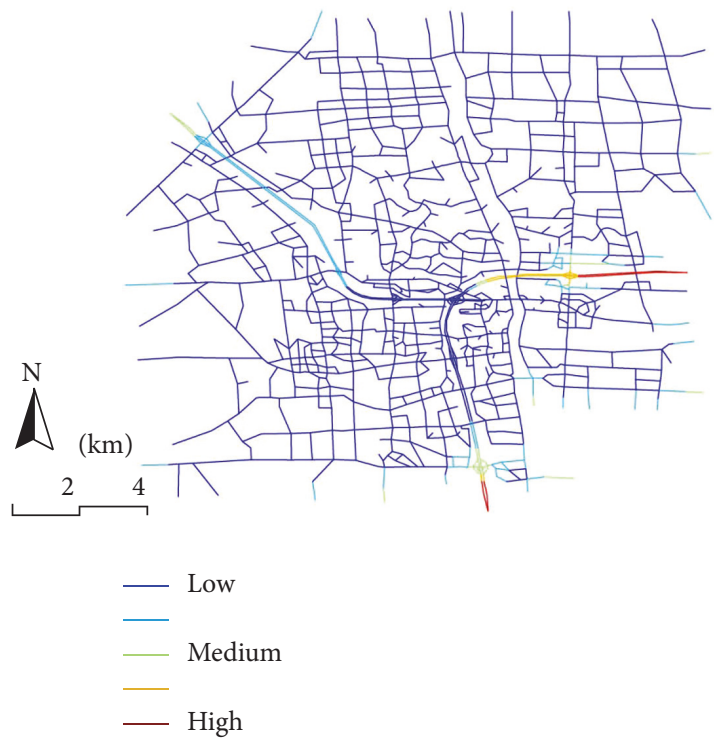

(a)

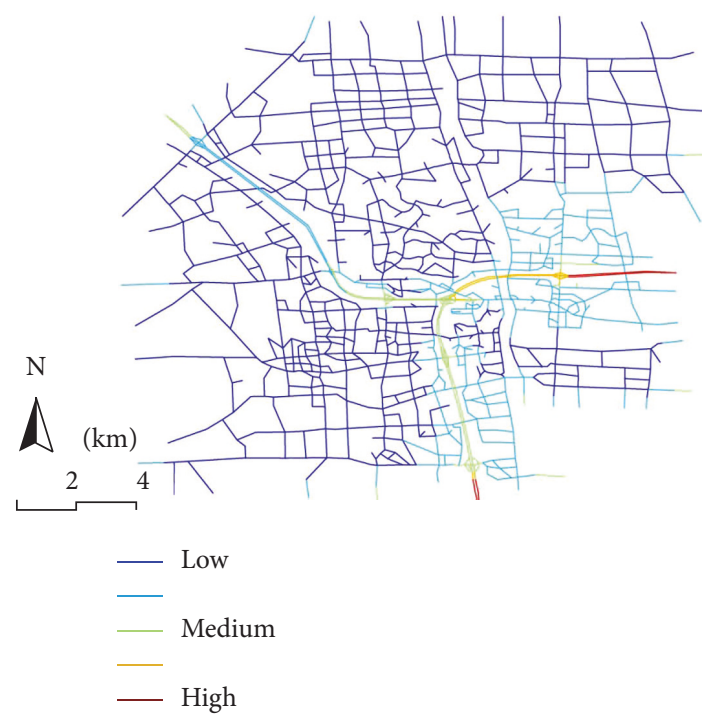

(c)

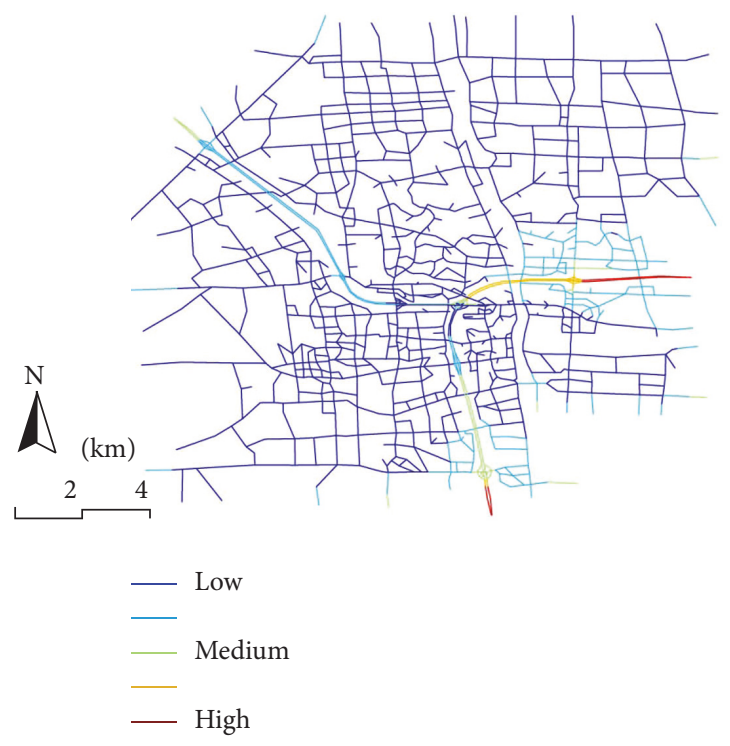

(b)

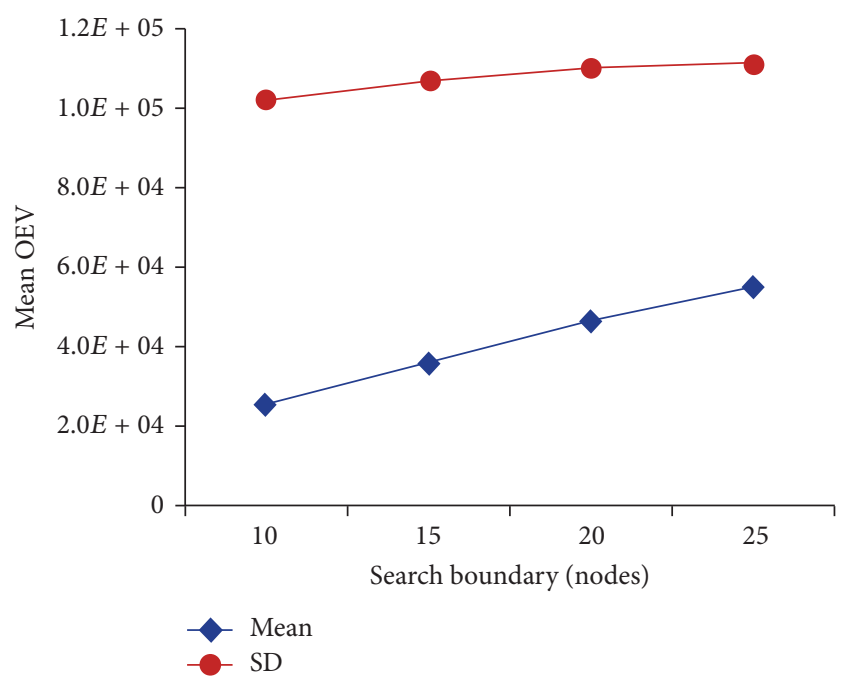

(d)

FIGURE 5: The OEV under different search boundaries: (a) 10 nodes; (b) 15 nodes; (c) 25 nodes; (d) the mean value and SD of all lines by search boundary. 
TABLE 2: Statistics of IEV in the scenario-based assessment.

\begin{tabular}{|c|c|c|c|c|c|c|}
\hline \multicolumn{7}{|c|}{ Inbound evacuation vulnerability (IEV) ${ }^{\dagger}$} \\
\hline \multicolumn{2}{|c|}{ Search boundary (nodes) } & 10 & 15 & 20 & 25 & 20 \\
\hline \multicolumn{2}{|c|}{ Scenario } & A & A & A & A & B \\
\hline \multirow{4}{*}{ Node } & Min & 0.0 & 903.7 & 2446.6 & 3120.7 & 2446.6 \\
\hline & Max & 1105780.0 & 1105780.0 & 1105780.0 & 1105780.0 & 1105780.0 \\
\hline & Mean & 28434.3 & 36492.5 & 44574.3 & 50717.3 & 51511.6 \\
\hline & SD & 95633.3 & 99190.1 & 101262.5 & 102112.0 & 101500.8 \\
\hline \multirow{4}{*}{ Line } & Min & 325.9 & 903.7 & 2568.8 & 3253.4 & 2568.8 \\
\hline & Max & 1105780.0 & 1105780.0 & 1105780.0 & 1105780.0 & 1105780.0 \\
\hline & Mean & 25357.6 & 33024.2 & 40849.8 & 46902.4 & 47589.6 \\
\hline & SD & 83144.0 & 86751.5 & 89340.9 & 90579.5 & 89696.6 \\
\hline \multicolumn{2}{|c|}{ Running time $^{\ddagger}$} & $2 \mathrm{~s}$ & $35 s$ & $7 \mathrm{~m}$ & $4 \mathrm{~h} 16 \mathrm{~m}$ & $7 \mathrm{~m}$ \\
\hline
\end{tabular}

${ }^{\dagger}$ Measurement unit is vehicles/(lanes $\left.* \mathrm{MPH}\right)$.

‡Time estimated using Windows 7 with Intel Core i7-2600 CPU @ 3.4 GHz and 8 GB RAM.

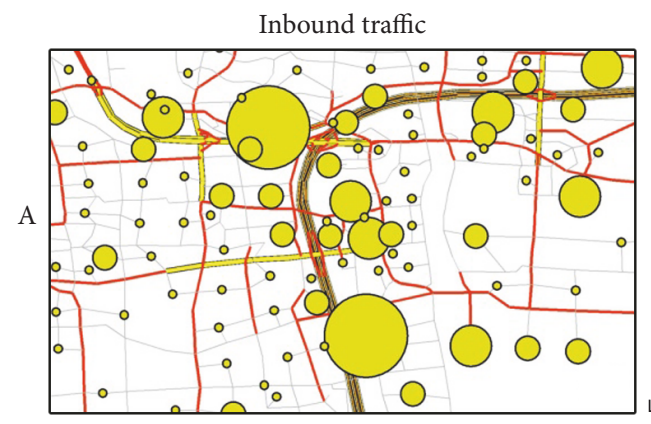

(a)

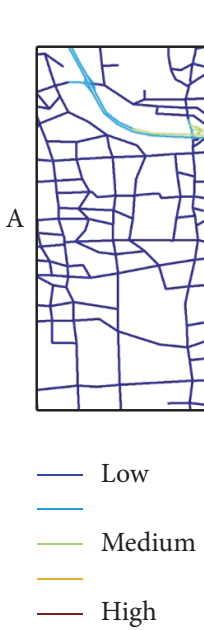

$\mathrm{EV}$
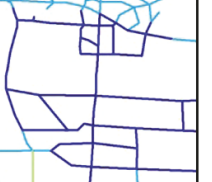

政

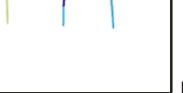

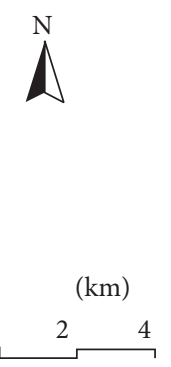

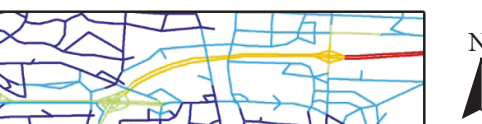

$\Lambda$

$(\mathrm{km})$

$\mathrm{km})$

\section{4}

$B$

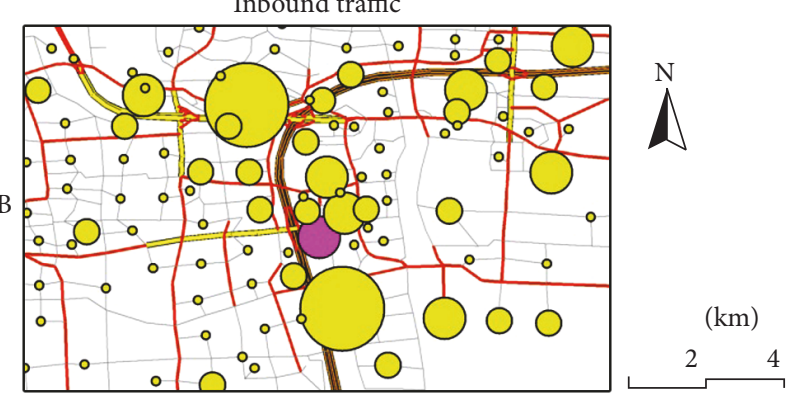

(b)
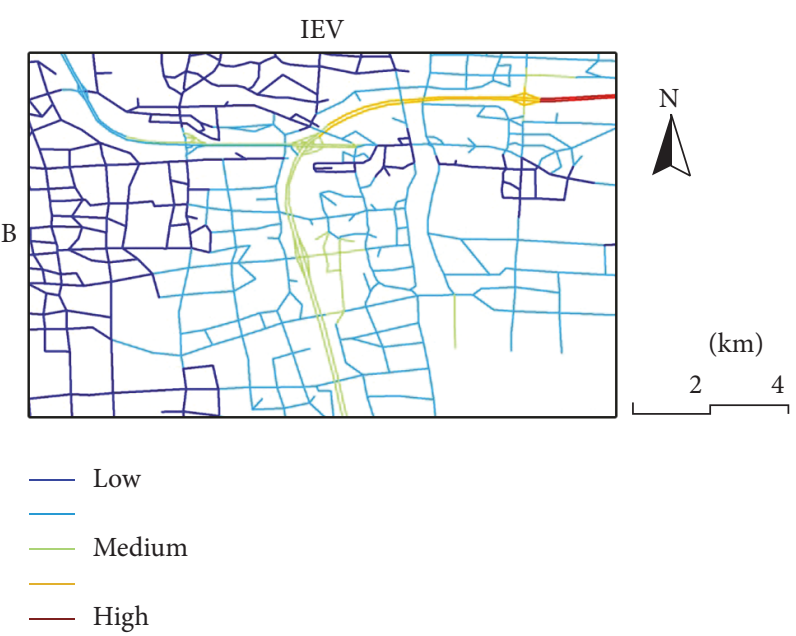

(c) (d)

FIgURE 6: The IEV faced by first responders in two scenarios: (a) original Scenario A; (b) Scenario B with an increased inbound traffic at the mall; (c) IEV of Scenario A; (d) IEV of Scenario B.

This section explores scenario-based assessment by analyzing the evacuation risk of first responders. The example in Figure 6 shows the inbound traffic patterns faced by first responders as they attempted to coordinate an unexpected no-notice evacuation in Scenario A (Figure 6(a)) and Scenario B (Figure 6(b)). The only difference between the two scenarios was an increase of 3,000 inbound vehicles at the major shopping mall in Dublin in Scenario B, as highlighted by a pink circle in Figure 6(b). The increase in traffic would lead to increased evacuation risk for first responders and can be quantified by the EVM model.

Figures 6(c) and 6(d) were derived, respectively, based on the IEV measure. Compared to the result of Scenario A, the IEV faced by first responders in Scenario B was 
intensified as seen from a slight increase at and near the mall; and the overall statistics are shown in Table 2 . This result reveals that the increase in inbound traffic in Scenario B will profoundly affect not only the difficulty of movement in the highly populated region but also the efficiency of rescue teams traveling down nearby neighborhoods. This finding further corroborates that the difficulty of dispatching a rescue team in a no-notice evacuation is subject to the connectivity of the transport system and that the difficulty level increases as the responders approach the region with dense traffic. A further comparison of Tables 1 and 2 reveals that IEV is slightly lower than the OEV (as shown in the bold text), indicating that the response team may experience a slightly lower level of difficulty in movement than the affected population leaving the site.

These differentiated vulnerabilities imply that coordinating a no-notice evacuation is beyond the rescue effort expended on alleviating the onsite impact. A pressing need is to provide a strategic plan in which the first responders can be navigated through a congested area with a high degree of uncertainty [42]. By identifying the spatial distribution of vulnerabilities faced by evacuees and first responders, proactive preparedness strategies, such as the rearrangement of emergency vehicles and warning systems, can be employed in the at-risk areas. In this respect, the EVM can help the emergency managers to map the vulnerability when a high degree of uncertainty is involved and address the problem in an all-hazard approach [43]. This model can also provide insights into scenario-based planning strategies and can help to answer questions about no-notice contingencies in a targeted region, such as "how would a road closure affect local evacuation?" and "how would the contraflow lane reversal affect travel for evacuees and first responders?"

\section{Conclusions}

Vulnerability is a core concept in emergency management and raises awareness of the geographic dimension that emergency planners and traffic coordinators must consider. As previous vulnerability research emphasized the socioeconomic factors in a disaster-prone area, road network connectivity and contingencies in no-notice evacuations were overlooked. By incorporating the facet of network topology and differentiating risks faced by evacuees and first responders, this paper develops an innovative network model to evaluate road network vulnerability in no-notice scenarios and can complement the overarching understanding of risk assessment.

Since many proactive planning strategies cannot be effectively implemented ahead of time in a no-notice evacuation, measuring evacuation vulnerability is heavily dependent on the configuration of transport networks (e.g., road capacity, direction of travel, and real-time traffic flow). In the proposed EVM model, this measurement differentiates the movement patterns of evacuees and first responders in order to accommodate their different evacuation needs when nonotice hazards arise.

This paper not only establishes a theoretical framework to measure evacuation vulnerability but also implements the model in a real-world transport network and tests the model validity. It shows that highways are more vulnerable in evacuations due to a limited number of outlets to disperse traffic. This finding indicates the importance of network topology in dictating difficulty of no-notice evacuations. The scenario-based assessment further stresses the robustness of the model that can account for the change of scenarios in facing an unpredictable event. These two facets of vulnerabilities demonstrate a promising example to address the complex issue of all-hazard emergency planning when a high level of uncertainty is involved [43].

Several caveats must be noted prior to any realistic interpretation of the model. First, as noted in many geographic studies, vulnerability is dependent on not only infrastructure but also people [44]. In other words, vulnerability varies across individuals in that each evacuee faces different challenges throughout the evacuation. Accounting for perceptions and course of action from the individual perspective is needed for comprehensive risk assessment. Thus, the validity of the model can be improved by accounting for individual behavioral variables, such as mode decisions [13, 40], routing strategies [30, 42, 45], and trip-chaining behaviors [46, 47]. Second, the road network vulnerability evaluated in the EVM is a synthetic analysis and lacks the capability to capture temporality. A particular evacuation scenario incorporates a multitude of dynamic environmental variables as events unfold [48]. The generalization of vulnerability cannot be used for a specific hazard and only serves as a reference for comprehensive mitigation plans. Thus, the vulnerability in the model predicts potential travel difficulties instead of realtime travel congestion. Furthermore, potential disruptions to transport infrastructure can inevitably arise during the course of evacuation. Evaluating vulnerability should take into account contingencies arising from a specific event, including loss of network nodes and arcs [5, 42]. To this end, a combined approach is needed to account for the uncertainty in the scenario-based assessment, for example, using a separate simulation method to validate if identified critical infrastructure is susceptible to a destructive scenario $[17,30]$. This combined approach will provide a solid context for vulnerability analysis and will accommodate situations where a changing nature exists.

\section{Conflicts of Interest}

The authors declare no conflicts of interest in the research.

\section{Acknowledgments}

This work was supported by the National Natural Science Foundation of China under Grant 41371489. The authors thank Dr. Morton O'Kelly and Center for Urban and Regional Analysis (CURA) at The Ohio State University for support of data collection.

\section{References}

[1] S. L. Cutter, "The vulnerability of science and the science of vulnerability," Annals of the Association of American Geographers, vol. 93, no. 1, pp. 1-12, 2003. 
[2] J. K. Mitchell, "Urban vulnerability to terrorism as hazard," in The Geographical Dimensions of Terrorism, S. L. Cutter, D. B. Richardson, and T. J. Wilbanks, Eds., pp. 17-25, Routledge, London, UK, 2003.

[3] K. A. Borden, M. C. Schmidtlein, C. T. Emrich, W. W. Piegorsch, and S. L. Cutter, "Vulnerability of U.S. cities to environmental hazards," Journal of Homeland Security and Emergency Management, vol. 4, no. 2, article 5, 2007.

[4] E. Taaffe, H. Gauthier, and O. Morton, Geography of Transport, Prentice-Hall, Englewood Cliffs, NJ, USA, 1996.

[5] T. C. Matisziw and A. T. Murray, "Modeling s-t path availability to support disaster vulnerability assessment of network infrastructure," Computers and Operations Research, vol. 36, no. 1, pp. 16-26, 2009.

[6] R. S. Russell and B. W. Taylor, Operations Management, Prentice Hall, Upper Saddle River, NJ, USA, 2002.

[7] B. T. Turgut, G. Tas, A. Herekoglu, H. Tozan, and O. Vayvay, "A fuzzy AHP based decision support system for disaster center location selection and a case study for Istanbul," Disaster Prevention and Management, vol. 20, no. 5, pp. 499-520, 2011.

[8] B. Flanagan, E. Gregory, E. Hallisey, J. Heitgerd, and B. Lewis, "A social vulnerability index for disaster management," Journal of Homeland Security and Emergency Management, vol. 8, no. 1, 2011.

[9] Z. F. Chen, X. Chen, Q. Li, and J. Chen, "The temporal hierarchy of shelters: a hierarchical location model for earthquake-shelter planning," International Journal of Geographical Information Science, vol. 27, no. 8, pp. 1612-1630, 2013.

[10] E. Urbina and B. Wolshon, "National review of hurricane evacuation plans and policies: a comparison and contrast of state practices," Transportation Research Part A: Policy and Practice, vol. 37, no. 3, pp. 257-275, 2003.

[11] Y. Xie, T. Arsava, and C. Zhang, "Impact of providing real-time traffic information on no-notice or short-notice evacuation efficiency-a case study," Journal of Homeland Security and Emergency Management, vol. 10, no. 2, pp. 411-431, 2013.

[12] Y.-C. Chiu, H. Zheng, J. Villalobos, and B. Gautam, "Modeling no-notice mass evacuation using a dynamic traffic flow optimization model," Institute of Industrial Engineers, vol. 39, no. 1, pp. 83-94, 2007.

[13] S. Liu, P. Murray-Tuite, and L. Schweitzer, "Incorporating household gathering and mode decisions in large-scale nonotice evacuation modeling," Computer-Aided Civil and Infrastructure Engineering, vol. 29, no. 2, pp. 107-122, 2014.

[14] C. Zimmerman and R. Brodesky, Using Highways for No-Notice Evacuations: Routes to Effective Evacuation Planning Primer Series, Federal Highway Administration, Office of Operations, Washington, DC, USA, 2007.

[15] G. G. Løvås, "On performance measures for evacuation systems," European Journal of Operational Research, vol. 85, no. 2, pp. 352-367, 1995.

[16] R. N. Lass, J. B. Kopena, E. A. Sultanik et al., "Coordination of first responders under communication and resource constraints," in Proceedings of the 7th International Joint Conference on Autonomous Agents and Multiagent Systems, pp. 1409-1412, International Foundation for Autonomous Agents and Multiagent Systems, Estoril, Portugal, 2008.

[17] A. T. Murray, T. C. Matisziw, and T. H. Grubesic, "A methodological overview of network vulnerability analysis," Growth and Change, vol. 39, no. 4, pp. 573-592, 2008.
[18] J. Chu and Y. Su, "Comprehensive evaluation index system in the application for earthquake emergency shelter site," Advanced Manufacturing Technology parts 1, 2, vol. 156-157, pp. 79-83, 2011.

[19] I. Armaş, "Multi-criteria vulnerability analysis to earthquake hazard of Bucharest, Romania," Natural Hazards, vol. 63, no. 2, pp. 1129-1156, 2012.

[20] R. Handfield, S. V. Walton, R. Sroufe, and S. A. Melnyk, "Applying environmental criteria to supplier assessment: a study in the application of the Analytical Hierarchy Process," European Journal of Operational Research, vol. 141, no. 1, pp. 7087, 2002.

[21] A. S. Fotheringham and D. W. S. Wong, "The modifiable areal unit problem in multivariate statistical analysis," Environment \& Planning A, vol. 23, no. 7, pp. 1025-1044, 1991.

[22] T. H. Grubesic and A. T. Murray, "Geographies of imperfection in telecommunication analysis," Telecommunications Policy, vol. 29, no. 1, pp. 69-94, 2005.

[23] A. Chen, C. Yang, S. Kongsomsaksakul, and M. Lee, "Networkbased acessibility measures for vulnerability analysis of degradable transportation networks," Networks and Spatial Economics, vol. 7, no. 3, pp. 241-256, 2007.

[24] M. A. P. Taylor, "Critical transport infrastructure in urban areas: Impacts of traffic incidents assessed using accessibility-based network vulnerability analysis," Growth and Change, vol. 39, no. 4, pp. 593-616, 2008.

[25] Y.-S. Myung and H.-J. Kim, "A cutting plane algorithm for computing k-edge survivability of a network," European Journal of Operational Research, vol. 156, no. 3, pp. 579-589, 2004.

[26] A. T. Murray and T. H. Grubesic, Critical Infrastructure: Reliability and Vulnerability, Springer, Berlin, Germany, 2007.

[27] T. J. Cova and R. L. Church, "Modelling community evacuation vulnerability using GIS," International Journal of Geographical Information Science, vol. 11, no. 8, pp. 763-784, 1997.

[28] R. L. Church and T. J. Cova, "Mapping evacuation risk on transportation networks using a spatial optimization model," Transportation Research Part C: Emerging Technologies, vol. 8, no. 1-6, pp. 321-336, 2000.

[29] Q. Li, X. Chen, J. Chen, and Q. Tang, "An evacuation risk assessment model for emergency traffic with consideration of urban hazard installations," Chinese Science Bulletin, vol. 55, no. 10, pp. 1000-1006, 2010.

[30] X. Chen, M.-P. Kwan, Q. Li, and J. Chen, "A model for evacuation risk assessment with consideration of pre- and postdisaster factors," Computers, Environment and Urban Systems, vol. 36, no. 3, pp. 207-217, 2012.

[31] J. Salter, "Risk management in the emergency management context," Australian Journal of Emergency Management, vol. 12, no. 4, pp. 22-28, 1997.

[32] S. W. Mitchell and E. Radwan, "Heuristic priority ranking of emergency evacuation staging to reduce clearance time," Transportation Research Record, no. 1964, pp. 219-228, 2006.

[33] S. Kim, S. Shekhar, and M. Min, "Contraflow transportation network reconfiguration for evacuation route planning," IEEE Transactions on Knowledge and Data Engineering, vol. 20, no. 8, pp. 1115-1129, 2008.

[34] S. Machiani, P. Murray-Tuite, A. Jahangiri et al., "No-notice evacuation management: ramp closures under varying budgets and demand scenarios," Transportation Research Record: Journal of the Transportation Research Board, no. 2376, pp. 27-37, 2013. 
[35] R. W. Perry and M. K. Lindell, "Preparedness for emergency response: guidelines for the emergency planning process," Disasters, vol. 27, no. 4, pp. 336-350, 2003.

[36] H. I. Hall, G. S. Haugh, P. A. Price-Green, V. R. Dhara, and W. E. Kaye, "Risk factors for hazardous substance releases that result in injuries and evacuations: data from 9 states," American Journal of Public Health, vol. 86, no. 6, pp. 855-857, 1996.

[37] M. OKelly and B. Mikelbank, "Social change and sustainable transport," in Social Change and Sustainable Transport, W. R. Black and P. Nijkamp, Eds., pp. 93-98, Indiana University Press, Bloomington, Ind, USA, 2002.

[38] J. Sohn, "Evaluating the significance of highway network links under the flood damage: an accessibility approach," Transportation Research Part A: Policy and Practice, vol. 40, no. 6, pp. 491506, 2006.

[39] C. Hohenemser, R. W. Kates, and P. Slovic, "The nature of technological hazard," Science, vol. 220, no. 4595, pp. 378-384, 1983.

[40] S. Liu, P. Murray-Tuite, and L. Schweitzer, "Analysis of child pick-up during daily routines and for daytime no-notice evacuations," Transportation Research Part A: Policy and Practice, vol. 46, no. 1, pp. 48-67, 2012.

[41] K. Zhang, X. Chen, S. Zhang, and B. Wilson-Gray, "Towards a healthy ride: locating public toilets in the Shanghai metro system," Applied Spatial Analysis and Policy, pp. 1-15, 2016.

[42] Z. Wang and S. Zlatanova, "Multi-agent based path planning for first responders among moving obstacles," Computers, Environment and Urban Systems, vol. 56, pp. 48-58, 2016.

[43] D. J. Odeh, "Natural hazards vulnerability assessment for statewide mitigation planning in Rhode Island," Natural Hazards Review, vol. 3, no. 4, pp. 177-187, 2002.

[44] S. L. Cutter, J. T. Mitchell, and M. S. Scott, "Revealing the vulnerability of people and places: a case study of Georgetown County, South Carolina," Annals of the Association of American Geographers, vol. 90, no. 4, pp. 713-737, 2000.

[45] H. Xu, Q. Li, X. Chen, J. Chen, J. Guo, and Y. Wang, "Logistical routing of park tours with waiting times: case of Beijing Zoo," Tourism Geographies, vol. 17, no. 2, pp. 208-222, 2015.

[46] X. Chen and M.-P. Kwan, "Choice set formation with multiple flexible activities under space-time constraints," International Journal of Geographical Information Science, vol. 26, no. 5, pp. 941-961, 2012.

[47] R. W. Perry, M. K. Lindell, and M. R. Greene, Evacuation Planning in Emergency Management, Lexington Books, Lexington, Mass, USA, 1981.

[48] K. Berdica, "An introduction to road vulnerability: what has been done, is done and should be done," Transport Policy, vol. 9, no. 2, pp. 117-127, 2002. 


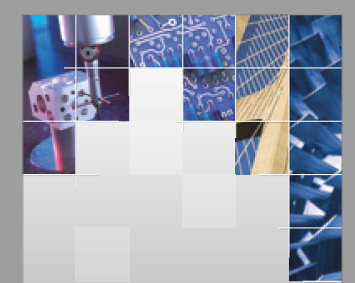

\section{Enfincering}
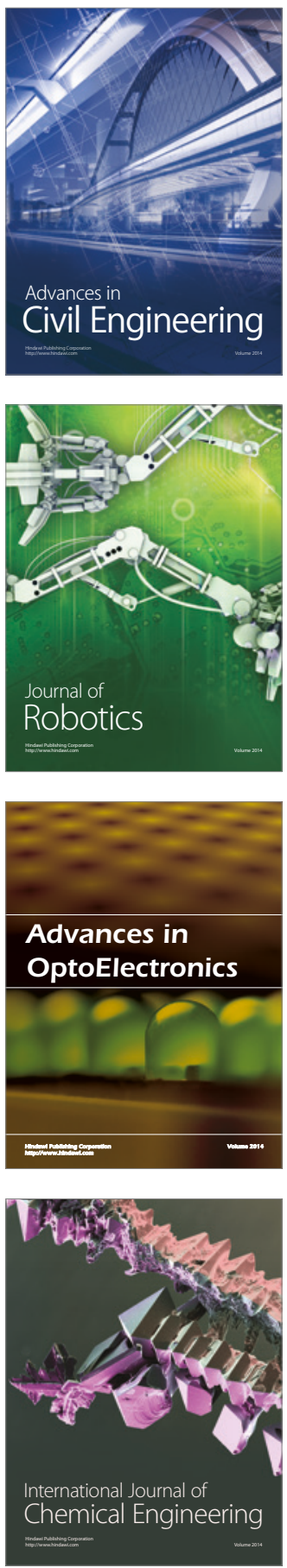

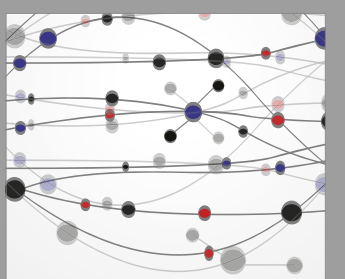

The Scientific World Journal

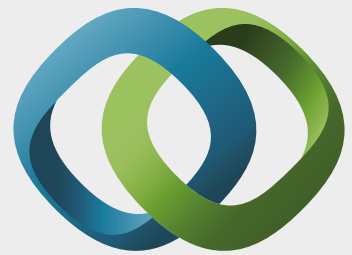

\section{Hindawi}

Submit your manuscripts at

https://www.hindawi.com
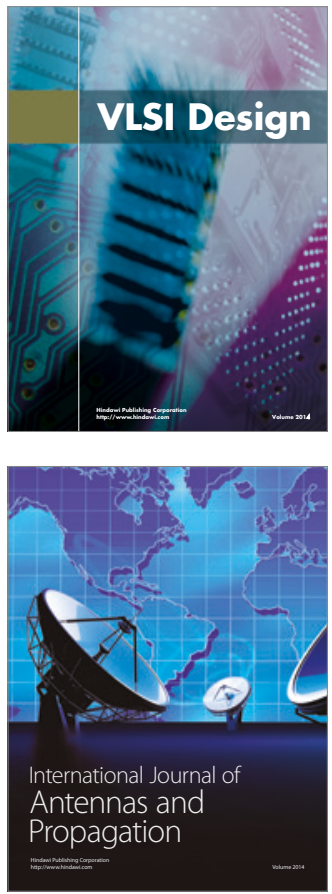

\section{Rotating}

Machinery
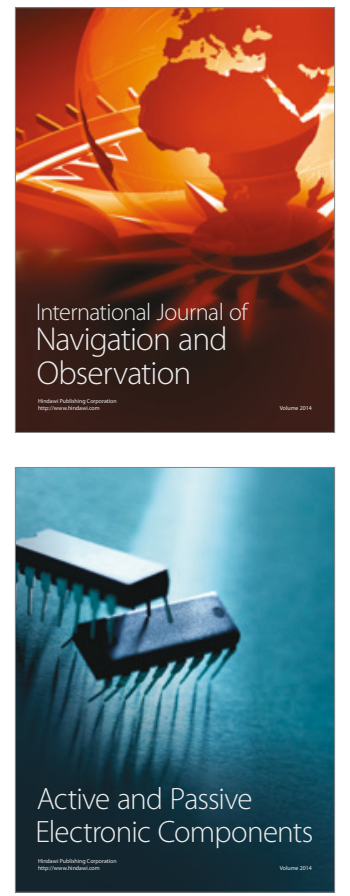
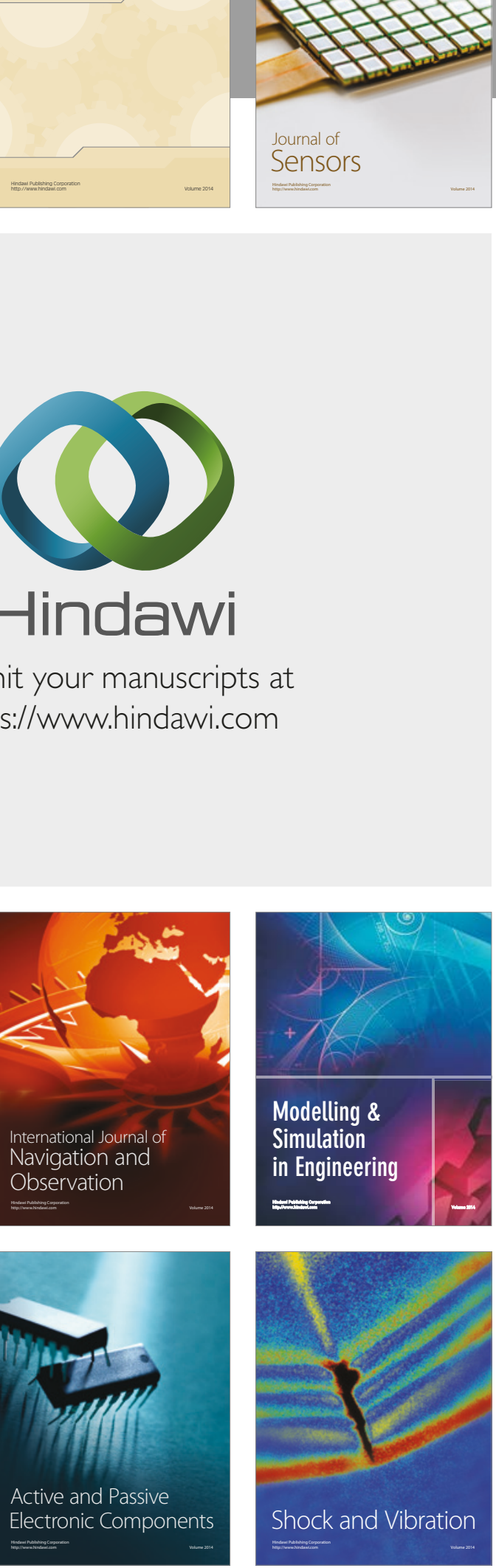
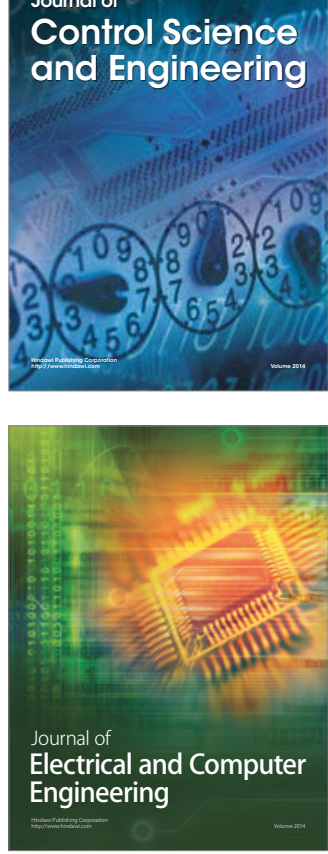

Distributed

Journal of

Control Science

and Engineering
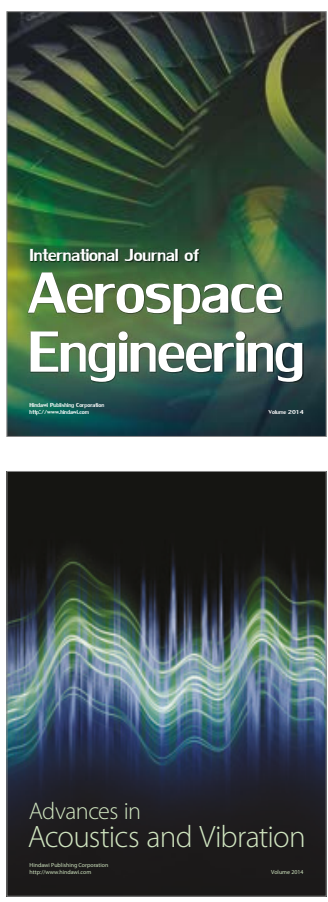

Sensor Networks 